\title{
Association of Hypomagnesemia in Type 2 Diabetic Patients with and without Peripheral Neuropathy
}

\author{
Anwar Ali Jamali ${ }^{*}$, Ghulam Mustafa Jamali ${ }^{1}$, Bhojo Mal Tanwani ${ }^{2}$, Ameer Ali Jamali ${ }^{3}$, \\ Yash Tanwani ${ }^{4}$, Naeem Mustafa Jamali ${ }^{5}$ \\ ${ }^{1}$ Department of Medicine, Peoples University of Medical and Health Sciences, Nawabshah, Pakistan \\ ${ }^{2}$ Department of Physiology, Peoples University of Medical and Health Sciences for Women, Nawabshah, Pakistan \\ ${ }^{3}$ Department of Paediatrics Medicine, Peoples University of Medical and Health Sciences for Women, Nawabshah, Pakistan \\ ${ }^{4}$ Ziauddin Medical University, Karachi, Pakistan \\ ${ }^{5}$ Liaquat University of Medical and Health Sciences, Jamshoro, Pakistan \\ Email: ^jamalianwarali@gmail.com
}

How to cite this paper: Jamali, A.A., Jamali, G.M., Tanwani, B.M., Jamali, A.A., Tanwani, Y. and Jamali, N.M. (2018) Association of Hypomagnesemia in Type 2 Diabetic Patients with and without Peripheral Neuropathy. Journal of Diabetes Mellitus, 8, 27-42.

https://doi.org/10.4236/jdm.2018.82004

Received: March 24, 2018

Accepted: May 14, 2018

Published: May 17, 2018

Copyright (c) 2018 by authors and Scientific Research Publishing Inc. This work is licensed under the Creative Commons Attribution International License (CC BY 4.0).

http://creativecommons.org/licenses/by/4.0/

\begin{abstract}
Background: Diabetes Mellitus is a wide-ranging metabolic disorder, which constitutes a most important physical condition dilemma in the world. Hypomagnesaemia accelerates the rate of diabetic complications. Objective: To analyze the association of serum magnesium $(\mathrm{Mg})$ in Type 2 Diabetes Mellitus with and without complication of peripheral neuropathy. Design: A cross sectional study. Setting: This research was carried out in medicine department, Peoples Medical College Hospital Nawabshah from May 2016-April 2017. Sample Size: Total 271 patients of both genders with Type 2 DM with and without peripheral neuropathy, each group after fulfilling the selection criteria were included. Material and Methods: After a short-lived consultation, the subjects were categorized for variable analyses like sex, age, Type 2 Diabetes Mellitus with and without peripheral neuropathy, duration of diabetes mellitus and presence of hypomagnesaemia. Clinical examination with monofilament was applied for diagnosis of peripheral neuropathy. Blood samples for magnesium analysis were collected in fasting condition. Results: In 271 diagnosed patients of Type 2 diabetes mellitus, 180 male and 91 were females. Peripheral neuropathy was observed in 136 subjects out of them 94 males and 42 were females. While 135 were without peripheral neuropathy out of them 86 males and 49 were females. Normal magnesium was seen in 119 (43.91\%) and low magnesium was present in 152 (56.09\%) patients overall. A decreased serum level of magnesium was observed in $56.09 \%$ diabetic subjects with peripheral neuropathy and $50 \%$ subjects with diabetes without peripheral neuropathy. Conclusion: Frequency of hypomagnesaemia is common in subjects with in Type $2 \mathrm{DM}$ with and without peripheral neuropathy.
\end{abstract}




\section{Keywords}

Type 2 Diabetes Mellitus, Hypomagnesaemia, Peripheral Neuropathy

\section{Introduction}

Diabetes mellitus is the progressively significant cause of morbidity and mortality throughout the globe [1]. In 2014 about 422 million individuals were suffering from diabetes mellitus throughout world and it is estimated that this count will touch to 642 million by the end of 2035 [2]. Micro and macro vascular complications are seen in subjects suffering from Diabetes, especially in T2DM [1]. In 2010 the number of diabetic sufferers was about 285 millions in the world, and it is estimated that by 2030 this will reach to 438 millions [3]. About 1.1 million diabetic patients died in 2005, and WHO (World Health Organization) had estimated that this figure will be doubled between 2005 and 2030 [4]. A cross survey conducted in rural and urban areas of Pakistan showed 19\% prevalence of diabetes mellitus [5]. Diabetes Mellitus (T2DM) is the most common type and about $90 \%$ to $95 \%$ diabetic subjects are from Type 2 DM [6]. Magnesium is a cation and is found abundantly, it is the second richest cation found intracellularly in the body [7].

In primary care clinics, peripheral neuropathy is found commonly. Peripheral neuropathy secondary to diabetes mellitus can be identified on examination by light touch and vibration test.

Sensory peripheral neuropathy is the dominant type and depends upon the duration of diabetes. Clinically it may be from mild, moderate to severe and initially there is no notable functional impairment [8]. In general population, peripheral neuropathy is noted with a rate of $2.4 \%$, it increases up to $8 \%$ in older population [9] [10]. Subjects with diabetes mellitus, Human Immunodeficiency Virus (HIV) infection, dysproteinemic ailments and those on chemotherapy are more vulnerable to develop peripheral neuropathy. In diabetic subjects the peripheral neuropathy (sensorimotor) is duration dependent and is found in $8 \%$ of subjects at diagnosis [11] [12], this increases with disease duration from $30 \%$ to $66 \%$, this depends how neuropathy is defined either clinically or by electrophysiologic criteria [13] [14].

Arpaci $\mathrm{D}$ et al. observed that hypomagnesemia is a frequent finding in subjects with diabetes. Hypomagnesemia promotes the risk and progress of complications due to diabetes. They found low levels of serum Magesium in 14.1\% subjects who were suffering from neuropathy due to diabetes [15].

Diabetes is a common metabolic syndrome, early recognization and prevention of hypomagnesemia may be helpful for treatment and control of diabetes. The outcome in terms of morbidity and mortality of diabetes related complications may be affected by giving additional supplements of magnesium in food or as drug therapy. Our main objective was to validate the association of serum 
magnesium (Mg) in Type 2 Diabetes Mellitus with and without complication of peripheral neuropathy.

\section{Material and Methods}

\subsection{Design of Study}

This is a prospective, case controlled, comparative and analytical study. Duration of study 01-years from May 2016-April 2017. Place of study Department of Medicine, Peoples Medical College Hospital Nawabshah (PMCH) Nawabshah.

\subsection{Operational Definition}

\subsubsection{Diagnosis of Hypomagnesaemia [16]}

Cutoff values for serum Magnesium levels

- Normal plasma Magnesium: 1.5 - $2.5 \mathrm{mEq} / \mathrm{L}$.

- Hypomagnesaemia: $<1.5 \mathrm{mEq} / \mathrm{L}$.

- Hypremagnesaemia: $>2.5 \mathrm{mEq} / \mathrm{L}$.

\subsubsection{Diagnosis of DM Type 2 [17]}

Type $2 \mathrm{DM}$ diagnosed through clinical history, examination and investigations with oral hypoglycemic drugs (OHA), insulin, medical records and according to American Diabetic Association Criteria.

1) Fasting Blood Sugar (FBS) values of $>126 \mathrm{mg} / \mathrm{dL}$ on two separate occasions.

2) 02 hours Post prandial sugar level $\geq 200 \mathrm{mg} / \mathrm{dL}$ (11.1 mmol/L).

3) Symptomatic patients, Random Blood Sugar (RBS) of $>200 \mathrm{mg} / \mathrm{dL}$ suggests diabetes.

4) Heamoglobin A1C (HBA1C) $\geq 6.5 \%(48 \mathrm{mmol} / \mathrm{mol})$.

\subsection{Diagnosis of Diabetic Peripheral Neuropathy}

Medical history, physical examination and neurological evaluation were used for diagnoses of peripheral neuropathy in T2DM subjects.

\subsection{Diabetic Peripheral (Sensory) Neuropathy [18]}

Definitions:

Possible Diabetic Sensory Peripheral Neuropathy (DSPN).

Presence of diminished sensation, numbness, pain (burning, prickling, stabbing or aching) of toes, feet or legs. Decreased peripheral sensation and decreased or absent ankle reflexes.

Probable Diabetic Sensory Peripheral Neuropathy (DSPN).

Presence of two or more features such as neuropathic symptoms (diminished sensation, numbness, pain), decreased peripheral sensation and decreased or absent ankle reflexes.

\subsection{Data Collection}

\subsubsection{Methodology of Study}

This is a hospital based study in which 271 subjects of T2DM who vi- 
sited/admitted in Medical department at Peoples Medical College Hospital Nawabshah (PMCH) Nawabshah. The patients in the study were included for History, Clinical Examination and Laboratory investigations (laboratory evaluation of $\mathrm{Mg}$ ). Venous blood samples were collected from all subjects of T2DM with and without Neuropathy. Rao-software for sample size calculation was used with $90 \%$ confidence level and margin of error 5\%, at the population of 1.6 million with $50 \%$ distribution response rate. Blood samples collected were stored prior to analysis. Automatic Analyzer was used to determine total Magnesium. Convenience/purposive sampling technique were used. Total 271 patients were included. After a short-lived consultation, the subjects were categorized for variable analyses like age, sex, T2DM with \& without neuropathy, length of diabetes and presence of hypomagnesaemia. A criterion for presence of peripheral neuropathy was applied to collect data. Blood samples for magnesium analysis were collected in fasting condition.

\subsubsection{Inclusion Criteria}

This hospital based study was targeted to only those patients who were above 30 years of age, known cases of type $2 \mathrm{DM}$. The subjects were divided in two groups. Group I diabetics with peripheral neuropathy and Group II diabetics without peripheral neuropathy.

\subsubsection{Exclusion Criteria}

Patients with acute and chronic complications of diabetes mellitus such as diabetic keto-acidosis, lactic-acidosis, Non-Ketotic Hyperosmolar coma, hypoglycemia hypertension, nephropathy and retinopathy were excluded. Patients on dialysis, Type $1 \mathrm{DM}$ and its complications, Magnesium supplementation, on drugs like diuretics or containing Magnesium. Diabetes Mellitus secondary to other diseases like Cushing syndrome, Acromegaly, and Gestational Diabetes were also excluded.

\subsection{Statistical Analysis}

Data was analyzed by using SPSS 20.0. Frequency \& percentages were computed for categorical variables like gender, and hypomagnesaemia. Mean and standard deviation were calculated for variables (quantitative) as age. Magnesium significance was seen in type $2 \mathrm{DM}$ in relation to age, gender, with and without peripheral neuropathy, duration of T2 DM, FBS and RBS, HBA1c and BMI (Body Mass Index) to see the impact on outcomes.

\section{Results}

There were 271 diabetic subjects, out of them 139 were with peripheral neuropathy while 132 were without peripheral neuropathy (Figure 1).

\subsection{Quantitative Variable Analyses}

The mean age of study subjects was 56.91 with standard deviation of 6.17 years; 


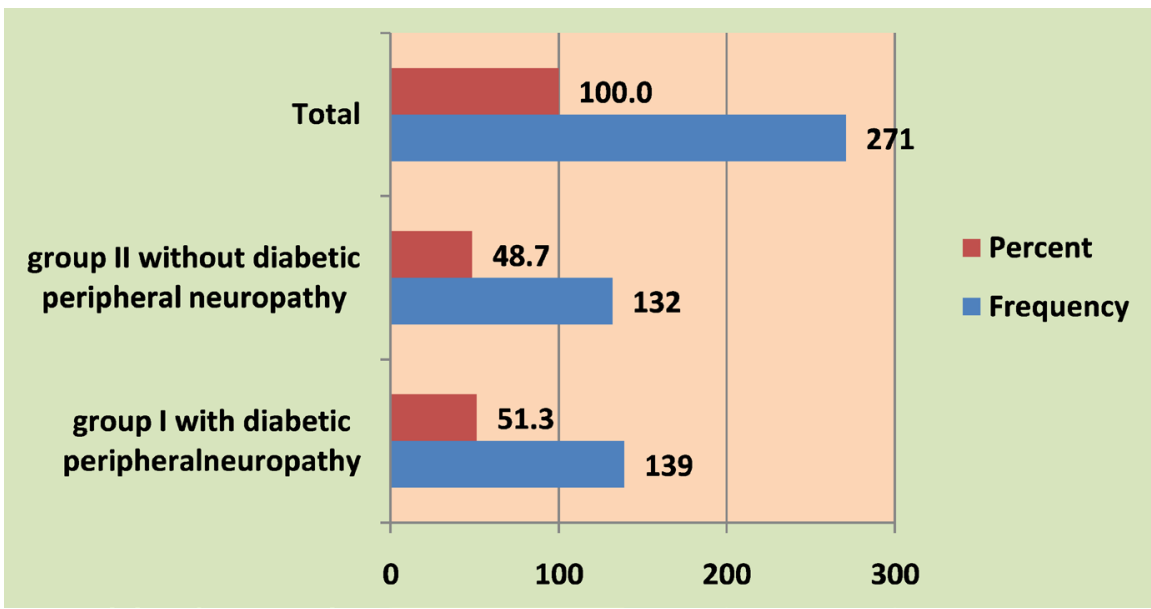

Figure 1 . Frequency $\& \%$ of T2DM with $\&$ without peripheral neuropathy. $n=271$.

minimum age 43 years while maximum was 73 years $(\mathrm{P}<0.001)$. The mean FBS level was $126.75 \mathrm{mg} / \mathrm{dl}$ with SD 25.006, minimum $80 \mathrm{mg} / \mathrm{dl}$ and maximum 200 $\mathrm{mg} / \mathrm{dl}(\mathrm{P}<0.002)$. The mean RBS level was $278.64 \mathrm{mg} / \mathrm{dl}$ with SD 60.94, minimum $180 \mathrm{mg} / \mathrm{dl}$ and maximum $450 \mathrm{mg} / \mathrm{dl}(\mathrm{P}<0.001)$. The mean serum magnesium level was $1.51 \mathrm{mg} / \mathrm{dl}$ with SD 0.354 , minimum $1.1 \mathrm{mg} / \mathrm{dl}$ and maximum 2.5 $\mathrm{mg} / \mathrm{dl}(\mathrm{P}<0.001)$. The mean systolic blood pressure (SBP) was 143.19 with SD 29.08, minimum $110 \mathrm{mmHg}$ and maximum $235 \mathrm{mmHg}(\mathrm{P}<0.001)$. The mean diastolic blood pressure (DBP) was 88.13 with SD 12.97, minimum $70 \mathrm{mmHg}$ and maximum $120 \mathrm{mmHg}(\mathrm{P}<0.001)$. The mean $\mathrm{HbA1c}$ level was $9.61 \%$ with standard deviation (SD) 1.62, minimum $6.50 \%$ and maximum $13.00 \%(\mathrm{P}<$ 0.001). Most of the diabetic patients were with duration of $5-10$ years, while in BMI over weight population was dominant. Significant statistical values are shown in Table 1.

\subsection{Demographic Qualitative Variable Analyses}

The study population consisted of 178 (65.7\%) male and 93 (34.3\%) were female subjects. Regarding the socio-demographic profile $94.8 \%$ were married and 5.2\% were unmarried. A large number $76.4 \%$ were from rural areas and $23.6 \%$ belonged to urban community. Majority of subjects with hypomagnesaemia were illiterate. In current study majority of subjects were manual workers $32.8 \%$, most of females $25.8 \%$ were house wives, $25.5 \%$ did not satisfy any occupation and $15.9 \%$ were office workers. As for socio economic status of subjects concerned [(Income < Rs: 20,000/m (lower income class/Poor Peoples), Income Rs 20000 to 28,000 (middle income class) and Income $>$ Rs 28,000 (middle upper income class)], 231 (85.2\%) belonged to poor back ground, 32 (11.8\%) were from middle class and $8(3 \%)$ belonged to upper middle class. A positive family history of DM was obtained in 106 (39.1\%) subjects and 165 (60.9\%) subjects have no family history of diabetes mellitus. In 200 (37.8\%) subjects there was no addiction history, while $65(24 \%)$ and $06(2.2 \%)$ were cigarette smokers and alcoholics (Figure 2). 


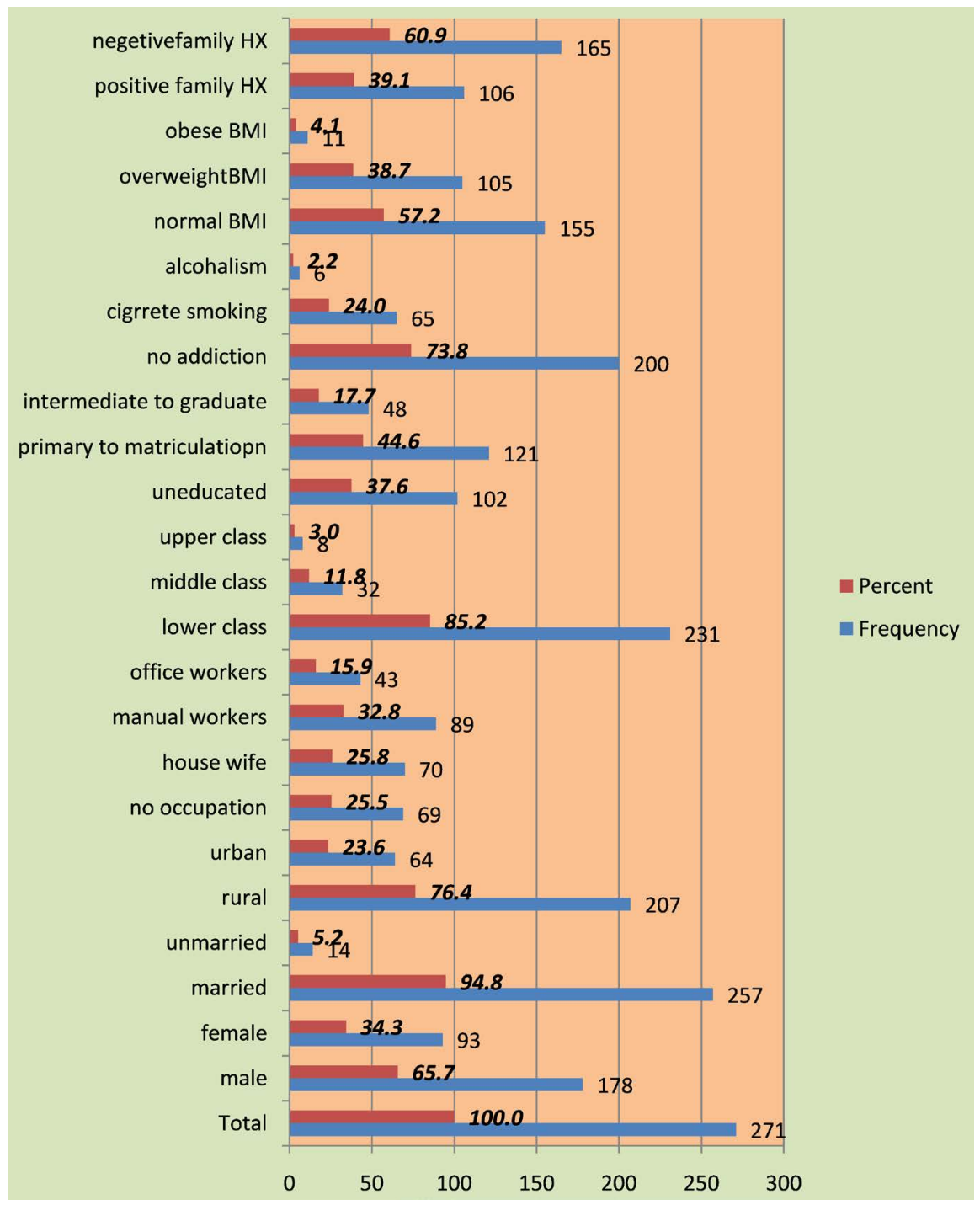

Figure 2. Demographic variables of T2DM. $n=271$.

Table 1. Statistics of different variables in diabetes with and without neuropathy. $\mathrm{n}=271$.

\begin{tabular}{cccccccc}
\hline & $\begin{array}{c}\text { Age In } \\
\text { Years }\end{array}$ & $\begin{array}{c}\text { Fasting Blood } \\
\text { Sugar }\end{array}$ & $\begin{array}{c}\text { Random Blood } \\
\text { Sugar }\end{array}$ & $\begin{array}{c}\text { Hemoglobin } \\
\text { A1C }\end{array}$ & Magnesium & $\begin{array}{c}\text { Systolic BP } \\
\text { mmHg }\end{array}$ & $\begin{array}{c}\text { Diastolic BP } \\
\text { mmHg }\end{array}$ \\
\hline N Valid & 271 & 271 & 271 & 271 & 271 & 271 & 271 \\
\hline Mean & 56.91 & 126.75 & 278.64 & 9.61 & 1.51 & 143.19 & 88.13 \\
Median & 55.00 & 125.00 & 265.00 & 9.00 & 1.40 & 135.00 & 85.00 \\
Std. Deviation & 6.17 & 25.00 & 60.94 & 1.62 & .35 & 29.08 & 12.97 \\
Minimum & 43.00 & 80.00 & 180.00 & 6.50 & 1.10 & 110.00 & 70.00 \\
Maximum & 73.00 & 200.00 & 450.00 & 13.00 & 2.50 & 235.00 & 120.00 \\
Chi-Square & 537.80 & 88.26 & 171.18 & 255.99 & 169.75 & 269.48 & 109.29 \\
df & 17 & 53 & 52 & 14 & 14 & 23 & 0.000 \\
Asymp. Sig. & 0.000 & 0.002 & 0.000 & 0.000 & 0.000 & 0.000 \\
\hline
\end{tabular}


Oral hypoglycemic drugs were used by 188 (69.4\%), insulin in $26(9.6 \%)$ and rest of patients $57(21.0 \%)$ did not use any medication. Drug compliance was unsatisfactory in $161(59.4 \%)$ patients. In 147 (54.2\%) subjects duration of DM was $<5$ years, in $89(32.8 \%)$ duration was from 5 - 10 years and 35 (12.9\%) subjects with duration $>10$ years respectively (Figure 3 ).

\subsection{Diabetes Neuropathy \& Magnesium Statistical Analyses}

Diabetic peripheral neuropathy was observed in 58 (49.2\%) subjects with normomagnesemia and in 81 (52.9\%) subjects with hypomagnesemia (Table 2).

Low serum magnesium was seen in total 153 (56.45\%) subjects with T2DM. Peripheral neuropathy was observed in 139 subjects out of them 58 (41.72\%) were with normal magnesium. While $81(58.28 \%)$ were with low magnesium, 132 subjects were without peripheral neuropathy 60 (45.45\%) were with normal magnesium level while 72 (54.55\%) were with low serum magnesium levels.

Normal magnesium was present in $118(43.54 \%)$ patients, 80 (67.8\%) male out of them 40 (33.9\%) in group1 with peripheral neuropathy \& 40 (33.3\%) without peripheral neuropathy in group 2, and out of 38 (32.2\%) female patients 18 (15.3\%) in group1 with peripheral neuropathy \& 20 (16.9\%) without peripheral neuropathy in group 2. Low magnesium was found in 153 (51.02\%) patients, out of them $98(64.8 \%)$ were male, 58 (37.9\%) with peripheral neuropathy in group 1 \& $40(26.1 \%)$ without peripheral neuropathy in group 2 . Out of $55(35.2 \%)$ female patients $23(15.0 \%)$ were with peripheral neuropathy in group 1 \& 32 (20.9\%) without peripheral neuropathy in group 2 (Table 2).

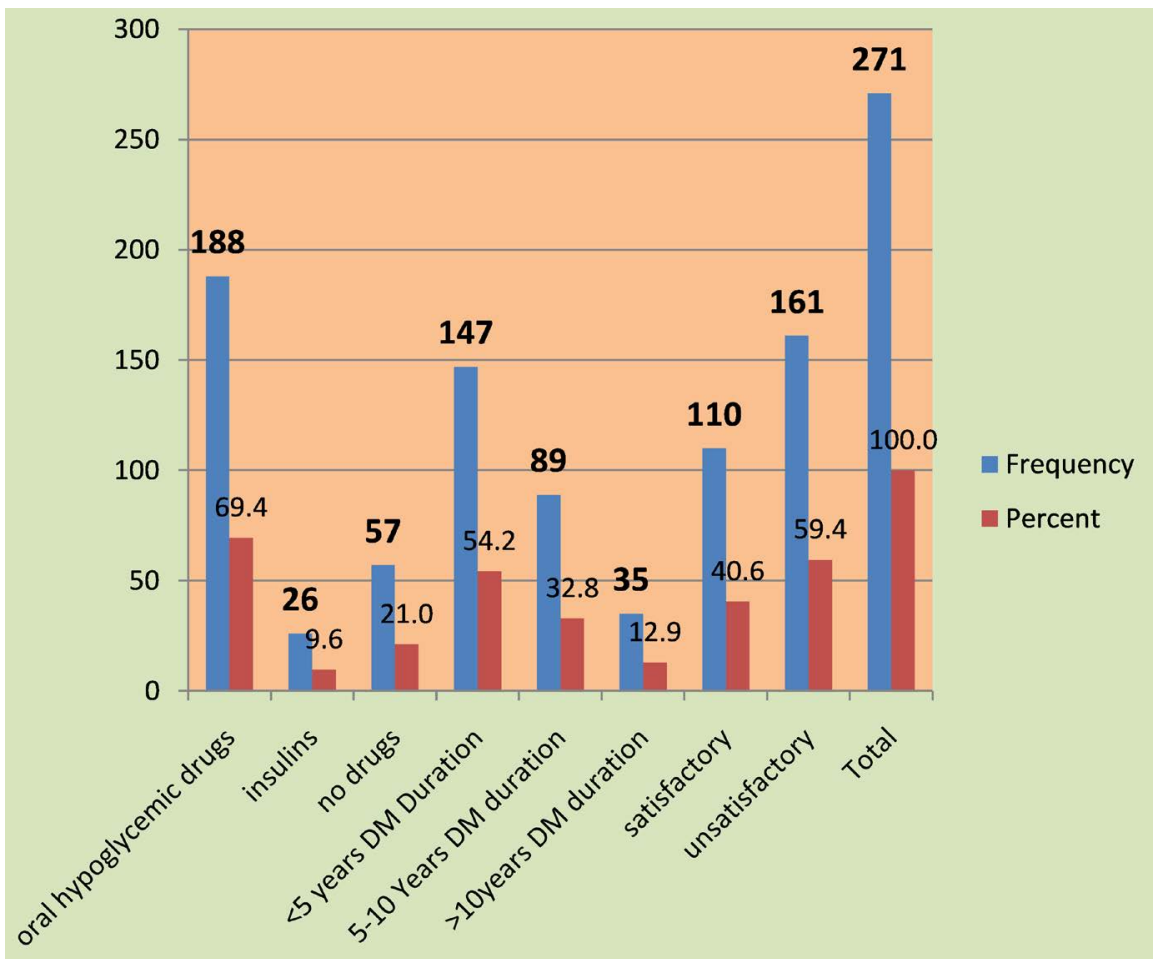

Figure 3. Ferquency \& $\%$ of T2DM drugs, duration \& compliance. 
Table 2. Cross-tabulation sex ${ }^{\star}$ neuropathy ${ }^{\star}$ serum magnesium. $\mathrm{n}=271$.

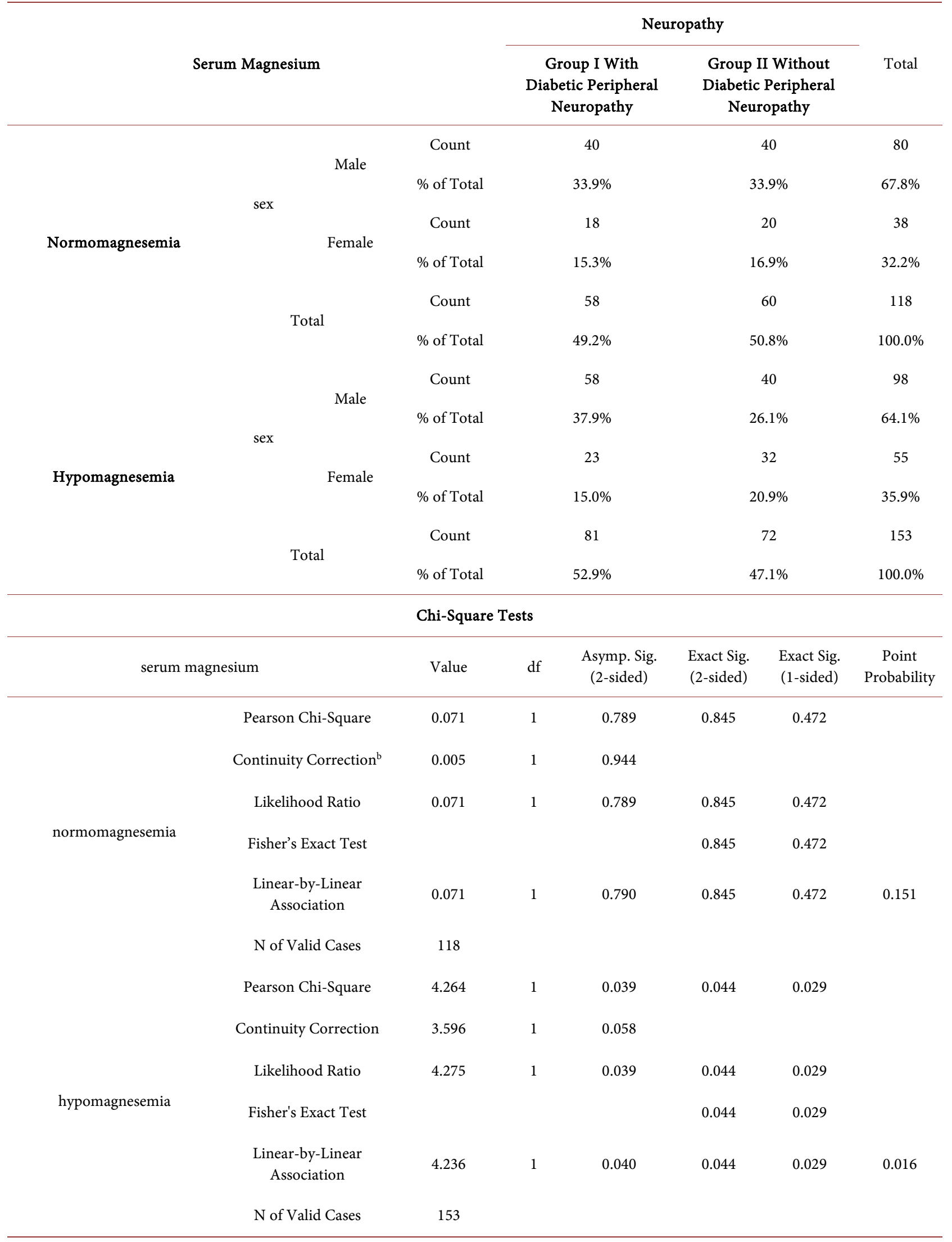


Chi-square test was applied for frequency and odds ratio to verify the potency of correlation. $\mathrm{P}=0.038$ in our study population in relation to hypomagnesaemia. Different chi-square was performed showing important statistical values. The odds ratio calculated was 1.1638 , with $95 \%$ confidence Interval 0.7197 to 1.8820 , with significance level $\mathrm{p}=\mathbf{0 . 5 3 6 2}$.

Number of valid cases in group 01 were 118 with normal serum magnesium level $(1.5-2.5 \mathrm{meq} / \mathrm{dl})$ and Pearson Chi-Square Value was 0.071 with $\mathrm{df} 1$, Asymp. Sig. (2-sided) 0.789. The Continuity Correction Value was 0.005 , with $\mathrm{df}$ 1and Asymp. Sig. (2-sided) 0.944. The likelihood ratio was 0.071 with df 1 and Asymp. Sig. (2-sided) 0.789. Fisher's Exact Test shown the Exact Sig. (2-sided) 1.845 and Exact Sig. (1-sided) 0.472. Linear by linear association value was 0.071 with df 1 and Asymp. Sig. (2-sided) 0.790. with point of probality 0.151 .

Number of valid cases in group 02 were 153 with hypomagnesemia $(<1.5$ meq/dl) and Pearson Chi-Square Value was 4.264 with df 1 and Asymp. Sig. (2-sided) 0.039. Continuity Correction Value was 3.596 with df 1 and Asymp. Sig. (2-sided) 0.058. The likelihood ratio was 4.275 with $\mathrm{df} 1$ and Asymp. Sig. (2-sided) value 0.039. Fisher's Exact Test had shown Exact Sig. (2-sided) value 0.044 and Exact Sig. (1-sided) value 0.029. Linear by linear association value was 4.236 with df 1 and Asymp. and Sig. (2-sided) value was 0.040 with point of probability 0.016 (Table 2).

In current study statistically significant correlation was found between different variables. There was statistically significant correlation of diabetic neuropathy with duration of diabetes mellitus and HBA1c levels. The correlation of duration of diabetes was also statistically significant with systolic and diastolic blood pressures. The correlation of compliance for diabetic dugs was significant with FBS.

No significant relation of diabetic neuropathy with drugs, compliance, FBs, RBS, SBP, DBP, BMI and other variables of study (Table 3 ).

\section{Discussion}

Type $2 \mathrm{DM}$ a universal disease of metabolism, it is dilemma of this era especially in Asian region as declared by WHO challenge for the future. More than half of diabetic population belongs to Asian countries India on the top of list.

Current study noted different basic characteristics of subjects in relation to diabetes with and without complications of peripheral neuropathy and its correlations with level of magnesium in serum. International studies are there on this issue but our setup still lacking. We had done a cross-sectional single centre study in our local population to compare the other available data with our setup and check the burden of disease and problem in our society. This will prove helpful for others to research more on this issue. Here we had assessed the association of hypomagnesaemia in T2DM with and without peripheral neuropathy. Hypomagnesaemia is common in diabetes mellitus; lot of studies in different complications of diabetes had shown that it was significantly lower in diabetics. 
Table 3. Correlations of different variables in T2DM. $\mathrm{n}=271$.

\begin{tabular}{|c|c|c|c|c|c|c|c|c|c|c|c|c|}
\hline & & Neuropathy & $\begin{array}{c}\text { Duration } \\
\text { Of DM }\end{array}$ & $\begin{array}{l}\text { Drugs } \\
\text { For DM }\end{array}$ & $\begin{array}{c}\text { Drugs } \\
\text { Compliance }\end{array}$ & FBS & RBS & HB Alc & $\mathrm{Mg}$ & $\begin{array}{c}\text { Systolic } \\
\text { B P } \\
\text { mmHg }\end{array}$ & $\begin{array}{c}\text { Diastolic } \\
\text { B P } \\
\text { mmHg }\end{array}$ & BMI \\
\hline \multirow{2}{*}{ Neuropathy } & $\begin{array}{l}\text { Pearson } \\
\text { Correlation }\end{array}$ & 1 & $0.287^{* *}$ & -0.038 & 0.114 & -0.071 & -0.091 & $0.120^{*}$ & 0.065 & 0.064 & 0.095 & -0.101 \\
\hline & $\begin{array}{c}\text { Sig. } \\
(2 \text {-tailed) }\end{array}$ & & 0.000 & 0.536 & 0.061 & 0.243 & 0.134 & 0.048 & 0.285 & 0.290 & 0.120 & 0.097 \\
\hline $\begin{array}{c}\text { Duration } \\
\text { Of }\end{array}$ & $\begin{array}{c}\text { Pearson } \\
\text { Correlation }\end{array}$ & $0.287^{* *}$ & 1 & 0.037 & 0.069 & -0.020 & -0.080 & 0.035 & 0.080 & $0.123^{*}$ & $0.141^{*}$ & -0.077 \\
\hline Diabetes & $\begin{array}{c}\text { Sig. } \\
(2 \text {-tailed) }\end{array}$ & 0.000 & & 0.541 & 0.255 & 0.741 & 0.189 & 0.569 & 0.190 & 0.042 & 0.020 & 0.205 \\
\hline $\begin{array}{l}\text { Drugs } \\
\text { For }\end{array}$ & $\begin{array}{c}\text { Pearson } \\
\text { Correlation }\end{array}$ & -0.038 & 0.037 & 1 & $-0.672^{* *}$ & $0.146^{*}$ & 0.098 & 0.012 & 0.006 & 0.009 & 0.044 & 0.066 \\
\hline Diabetes & $\begin{array}{c}\text { Sig. } \\
\text { (2-tailed) }\end{array}$ & 0.536 & 0.541 & & 0.000 & 0.016 & 0.107 & 0.841 & 0.920 & 0.882 & 0.473 & 0.280 \\
\hline $\begin{array}{c}\text { Compliance } \\
\text { For }\end{array}$ & $\begin{array}{c}\text { Pearson } \\
\text { Correlation }\end{array}$ & 0.114 & 0.069 & $-0.672^{* *}$ & 1 & -0.115 & -0.115 & 0.003 & -0.013 & 0.033 & -0.003 & $-0.150^{*}$ \\
\hline Drugs & $\begin{array}{c}\text { Sig. } \\
\text { (2-tailed) }\end{array}$ & 0.061 & 0.255 & 0.000 & & 0.060 & 0.058 & 0.964 & 0.829 & 0.593 & 0.962 & 0.014 \\
\hline \multirow{2}{*}{$\begin{array}{l}\text { Fasting } \\
\text { Blood } \\
\text { Sugar }\end{array}$} & $\begin{array}{c}\text { Pearson } \\
\text { Correlation }\end{array}$ & -0.071 & -0.020 & $0.146^{*}$ & -0.115 & 1 & $0.863^{* *}$ & -0.013 & -0.022 & -0.044 & -0.038 & 0.053 \\
\hline & $\begin{array}{c}\text { Sig. } \\
\text { (2-tailed) }\end{array}$ & 0.243 & 0.741 & 0.016 & 0.060 & & 0.000 & 0.829 & 0.720 & 0.472 & 0.529 & 0.384 \\
\hline \multirow{2}{*}{$\begin{array}{c}\text { Random } \\
\text { Blood } \\
\text { Sugar }\end{array}$} & $\begin{array}{c}\text { Pearson } \\
\text { Correlation }\end{array}$ & -0.091 & -0.080 & 0.098 & -0.115 & $0.863^{* *}$ & 1 & -0.005 & -0.058 & -0.040 & -0.033 & 0.092 \\
\hline & $\begin{array}{c}\text { Sig. } \\
\text { (2-tailed) }\end{array}$ & 0.134 & 0.189 & 0.107 & 0.058 & 0.000 & & 0.931 & 0.338 & 0.512 & 0.589 & 0.129 \\
\hline \multirow{2}{*}{$\begin{array}{c}\text { Hemoglobin } \\
\text { A1C }\end{array}$} & $\begin{array}{c}\text { Pearson } \\
\text { Correlation }\end{array}$ & $0.120^{*}$ & 0.035 & 0.012 & 0.003 & -0.013 & -0.005 & 1 & 0.036 & -0.080 & -0.055 & -0.053 \\
\hline & $\begin{array}{c}\text { Sig. } \\
\text { (2-tailed) }\end{array}$ & 0.048 & 0.569 & 0.841 & 0.964 & 0.829 & 0.931 & & 0.556 & 0.188 & 0.364 & 0.389 \\
\hline \multirow{2}{*}{ Magnesium } & $\begin{array}{c}\text { Pearson } \\
\text { Correlation }\end{array}$ & 0.065 & 0.080 & 0.006 & -0.013 & -0.022 & -0.058 & 0.036 & 1 & 0.058 & 0.056 & 0.071 \\
\hline & $\begin{array}{c}\text { Sig. } \\
\text { (2-tailed) }\end{array}$ & 0.285 & 0.190 & 0.920 & 0.829 & 0.720 & 0.338 & 0.556 & & 0.338 & 0.362 & 0.244 \\
\hline \multirow{2}{*}{$\begin{array}{l}\text { Systolic } \\
\text { BP } \\
\mathrm{mmHg}\end{array}$} & $\begin{array}{l}\text { Pearson } \\
\text { Correlation }\end{array}$ & 0.064 & $0.123^{*}$ & 0.009 & 0.033 & -0.044 & -0.040 & -0.080 & 0.058 & 1 & $0.955^{* *}$ & -0.055 \\
\hline & $\begin{array}{c}\text { Sig. } \\
\text { (2-tailed) }\end{array}$ & 0.290 & 0.042 & 0.882 & 0.593 & 0.472 & 0.512 & 0.188 & 0.338 & & 0.000 & 0.364 \\
\hline \multirow{2}{*}{$\begin{array}{c}\text { Diastolic } \\
\text { BP } \\
\mathrm{mmHg}\end{array}$} & $\begin{array}{l}\text { Pearson } \\
\text { Correlation }\end{array}$ & 0.095 & $0.141^{*}$ & 0.044 & -0.003 & -0.038 & -0.033 & -0.055 & 0.056 & $0.955^{* *}$ & 1 & -0.081 \\
\hline & $\begin{array}{c}\text { Sig. } \\
\text { (2-tailed) }\end{array}$ & 0.120 & 0.020 & 0.473 & 0.962 & 0.529 & 0.589 & 0.364 & 0.362 & 0.000 & & 0.184 \\
\hline \multirow{2}{*}{ BMI } & $\begin{array}{c}\text { Pearson } \\
\text { Correlation }\end{array}$ & -0.101 & -0.077 & 0.066 & $-0.150^{*}$ & 0.053 & 0.092 & -0.053 & 0.071 & -0.055 & -0.081 & 1 \\
\hline & $\begin{array}{c}\text { Sig. } \\
\text { (2-tailed) }\end{array}$ & 0.097 & 0.205 & 0.280 & 0.014 & 0.384 & 0.129 & 0.389 & 0.244 & 0.364 & 0.184 & \\
\hline
\end{tabular}

**. Correlation is significant at the 0.01 level (2-tailed); ${ }^{*}$. Correlation is significant at the 0.05 level (2-tailed). 
Low income class, no or lower education profile especially health education, unemployment, no occupation, house wives, or labor category (only $15.9 \% \mathrm{n}=$ 271 were office workers) and others, these factors contribute to deficiency of magnesium in nutrition and ultimately hypomagnesaemia and this could be the reason for speedy rise in diabetes and peripheral neuropathy.

Hypomagnesemia can lead potentially serious complications as ventricular arrhythmias, coronary artery vasospasm, and sudden cardiac death. Magnesium has well recognized importance, high and low levels can be found in patients [19]. Magnesium was also called as forgotten cation [20] [21].

Magnesium is the second most common cation found in the cell and is the fourth common divalent cation in the body and is element of interest for researches. It is present in three compartments of body, major portion about $65 \%$ is present in bones, $34 \%$ inside cells and $1 \%$ of magnesium is extracellular. Magnesium plays a central role in many metabolic reactions, such as DNA and protein synthesis, hormone receptor binding and neurotransmission. Magnesium is constituent of GTP-ase. It acts as cofactor for $\mathrm{Na}+/ \mathrm{K}+\mathrm{ATP}$-ase, Adenylate Cyclase and Phospho-fructokinase. It plays an essential role in a lot of biochemical reactions in body and also important for carbohydrate metabolism and effects the activity and release of insulin [22] [23] [24]. Subjects with type 2 diabetes mellitus are more prone to develop hypomagnesaemia as compared with non diabetic subjects. Clinicians are still giving less importance to the association between hypomagnesaemia and chronic complications of diabetes.

Current research evaluates magnesium metabolism, frequency of low magnesium and complications (especially peripheral neuropathy) associated with diabetes mellitus.

Present study had found hypomagnesaemia in total $56.45 \%$ subjects with T2DM these findings are nearby other available studies.

Prevalence of hypomagnesaemia among type 2 diabetes mellitus ranges from $13.5 \%$ to $47.7 \%$ respectively. Many factors contribute in this such as, insufficient intake, autonomic dysfunction, and alteration in metabolism of insulin, glomerular hyper-infiltration, osmotic diuresis, metabolic acidosis and decreased levels of serum potassium levels. Unsatisfactory glycemic control, CAD (coronary artery disease), hypertension, diabetic peripheral neuropathy, nephropathy, retinopathy and foot ulcers are linked with hypomagnesaemia. Increasing prevalence of low magnesium in type 2 diabetic patients is thought to be multifactorial [25].

Findings of current study regarding serum magnesium level concluded that hypomagnesaemia was present in both groups of diabetes mellitus but the frequency was more in diabetics with peripheral neuropathy as compared in subjects without peripheral neuropathy.

Subjects with hypomagnesaemia have high risk of diabetic complications and are observed with increased disease progression. Reabsorption of $\mathrm{Mg}^{2+}$ in the kidneys is reduced in insulin resistance. Insulin sensitivity and glucose metabolism both are improved when $\mathrm{Mg}^{2+}$ supplements are given to diabetic subjects. 
Another risk agent for hypomagnesaemia is the intestinal malabsorption for $\mathrm{Mg}^{2+}$ which is observed in diabetic neuropathy during episodes of diarrhea. Insulin resistance index is improved and HBA1c is decreased in diabetic subjects when they are given magnesium chloride $\left(\mathrm{MgCl}_{2}\right)$ [26]

Findings of current study concluded that there were high levels of HBA1C in diabetic subjects. The mean HBA1C levels in present study were $9.61 \%$.

Increased intake of magnesium reduces the risk of complications related with type 2 DM [27].

Present study favors that statement because there were low levels of magnesium in diabetic complication of neuropathy. This need further support by giving additional supplements of magnesium.

It is important to monitor $\mathrm{Mg}$ levels regularly in Type 2 diabetic subjects as hypomagnesaemia is related to poor glycemic control and thus lead to higher occurrence of diabetes related complications such as peripheral neuropathy, nephropathy, retinopathy and foot ulcerations. More studies are required in T2DM subjects on the part of magnesium supplements in our communities [28].

Different studies conducted previously on relation of diabetes and its different complication shown that there was strong association of hypomagnesaemia and diabetic foot ulcers. Diabetic peripheral neuropathy is also a strong risk factor for development of foot ulcers as concluded in past research. Ashok et al found hypomagnesaemia in $57 \%$ of patients with different grades of foot ulcers [29], while AA Jamali et al. found $60.9 \%$ of foot ulcer patients [30].

Neuropathy was observed in $71.42 \%$ patients with low magnesium levels as compared to $28.42 \%$ patients with normal magnesium levels. Researches had proved that in subjects with diabetic peripheral neuropathy, intracellular magnesium levels are decreased [31] and there is improvement in the nerve conduction in these subjects after magnesium supplements [32].

Jamali AA et al. found that frequency of hypomagnesaemia is common in T2DM with and without hypertension. A decreased serum level of magnesium was observed in 52.04\% hypertensive subjects with diabetes and 50\% non-hypertensive subjects with diabetes [33].

In current research we had found Low serum magnesium in total 153 (56.45\%) subjects with T2DM. Peripheral neuropathy was observed in 139 subjects out of them 58 (41.72\%) were with normal magnesium. While 81 (58.28\%) were with low magnesium, 132 subjects were without peripheral neuropathy $60(45.45 \%)$ were with normal magnesium level while $72(54.55 \%)$ were with low serum magnesium levels. In present research there was strong correlation of peripheral neuropathy and drugs and $\mathrm{HbA1C}$ levels.

Low serum magnesium in subjects with peripheral diabetic neuropathy could be free interpreter of disease progress. Constant low levels of magnesium lead to higher serum sugar levels. Extent of magnesium reduction and insulin resistance associates positively with development and worsening of peripheral neuropathy and hyperglycemia may lead to development of different other complications thus increasing mortality and morbidity. Outcomes of current research can help 
to treat hypomagnesaemia and arrest progress of neuropathy. In current study low magnesium levels are observed in T2DM subjects with and without peripheral neuropathy.

\section{Strengths and Limitations}

This was a small sample size study, in a local area, with bias but this study was an important opening of research on magnesium and its effects in diabetes with different complications in our setup. No study was conducted yet on magnesium in diabetes with and without neuropathy in our setup; this study will guide the impact of magnesium on diabetes and to prevent the complication like neuropathy by giving magnesium as drug or in food supplements.

\section{Recommendations}

A multicenter research shall be carried out to observe the magnesium effects on diabetes with and without complications of peripheral neuropathy. All patients with diabetes should be investigated for serum magnesium level, if deficient should be corrected on priority basis. Hypomagnesaemia should be corrected on priority basis because studies shown that it affects the prognosis and outcome of diabetes.

\section{Conclusion}

The occurrence of hypomagnesaemia was increased in Type 2 diabetes mellitus in subjects suffering from peripheral neuropathy. Patients with diabetic neuropathy had considerable decreased serum values of magnesium. This recommends that intermittent screening of serum magnesium levels in diabetic subjects can be helpful in early detection and this suggests that periodic monitoring of $\mathrm{Mg}$ levels in diabetic patients may be helpful in early recognition and better-quality management of diabetic neuropathy.

\section{Acknowledgements}

\section{Authors' Contributions}

Anwar Ali Jamali designed the study protocol, planned analyses, and manuscript draft. Ghulam Mustafa Jamali had done statistical analyses and data interpretation and drafting. Other authors reviewed manuscript draft, critically, contributed to analysis, discussion and interpretation of the data, with writing of the manuscript to data collection.

\section{Funding}

No funding from any institutional, governmental/non-governmental organizations.

\section{Disclosure}

Authors have declared no conflict of interest. 


\section{References}

[1] American Diabetes Association (2015) Standards of Medical Care in Diabetes-2015: Summary of Revisions. Diabetes Care, 38, S4. https://doi.org/10.2337/dc15-S003

[2] Gentile, G., Mastroluca, D., Ruggenenti, P. and Remuzzi, G. (2014) Novel Effective Drugs for Diabetic Kidney Disease. Expert Opinion on Emerging Drugs, 19, 571-601. https://doi.org/10.1517/14728214.2014.979151

[3] Diabetes Facts (2010). https://www.worlddiabetesfoundation.org/composite-35.html

[4] Sierra, G.N. (2009) The Global Pandemic of Diabetes. African Journal of Diabetes Medicine. Global Pandemic.indd.4-8.

http://indexmedicus.afro.who.int/iah/fulltext/AJDM/vol\%2017\%20n2/Global\%20pa ndemic\%204-8.pdf

[5] Shera, A.S., Jawad, F. and Maqsood, A. (2007) Prevalence of Diabetes in Pakistan. Diabetes Research and Clinical Practice, 76, 219-222. https://doi.org/10.1016/j.diabres.2006.08.011

[6] American Diabetes Association (2009) Diagnosis and Classification of Diabetes Mellitus. Diabetes Care, 32, S62-S67. https://doi.org/10.2337/dc09-S062

[7] Glasdam, S.M., Glasdam, S. and Peters, G.H. (2016) The Importance of Magnesium in the Human Body: A Systematic Literature Review. Advances in Clinical Chemistry, 73, 169-193. https://doi.org/10.1016/bs.acc.2015.10.002

[8] Watson, J.C. and Dyck, P.J. (2015) Peripheral Neuropathy: A Practical Approach to Diagnosis and Symptom Management. Mayo Clinic Proceedings, 90, 940-951.

https://doi.org/10.1016/j.mayocp.2015.05.004

[9] Martyn, C.N. and Hughes, R.A. (1997) Epidemiology of Peripheral Neuropathy. Journal of Neurology, Neurosurgery, and Psychiatry, 62, 310-318. https://doi.org/10.1136/jnnp.62.4.310

[10] Italian General Practitioner Study Group (IGPSG) (1995) Chronic Symmetric Symptomatic Polyneuropathy in the Elderly: Afield Screening Investigation in Two Italian Regions, I: Prevalence and General Characteristics of the Sample. Neurology, 45, 1832-1836. https://doi.org/10.1212/WNL.45.10.1832

[11] Partanen, J., Niskanen, L., Lehtinen, J., Mervaala, E., Siitonen, O. and Uusitupa, M. (1995) Natural History of Peripheral Neuropathy in Patients with Non-Insulin-Dependent Diabetes Mellitus. The New England Journal of Medicine, 333, 89-94. https://doi.org/10.1056/NEJM199507133330203

[12] Boulton, A.J.M. (2005) Management of Diabetic Peripheral Neuropathy. Clinical Diabetes, 23, 9-15. https://doi.org/10.2337/diaclin.23.1.9

[13] Dyck, P.J., Kratz, K.M., Karnes, J.L., et al. (1993) The Prevalence by Stagedseverity of Various Types of Diabetic Neuropathy, Retinopathy, and Nephropathy in a Population-Based Cohort: The Rochester Diabetic Neuropathy Study. Neurology, 43, 817-824. https://doi.org/10.1212/WNL.43.4.817

[14] Gregg, E.W., Sorlie, P., Paulose-Ram, R., et al. (2004) Prevalence of Lower-Extremity Disease in the US Adult Population $\geq 40$ Years of Age with and without Diabetes: 1999-2000 National Health and Nutrition Examination Survey. Diabetes Care, 27, 1591-1597. https://doi.org/10.2337/diacare.27.7.1591

[15] Arpaci, D., Tocoglu, A.G., Ergenc, H., Korkmaz, S., Ucar, A. and Tamer, A. (2015) Associations of Serum Magnesium Levels with Diabetes Mellitus and Diabetic Complications. Hippokratia, 19, 153-157.

[16] Lee, M. (2013) Basic Skills in Interpreting Laboratory Data. 5th Edition, American 
Society of Health-System Pharmacists.

[17] American Diabetes Association (2016) Standards of Medical Care in Diabetes-2016. Diabetes Care, 39, S4-S5.

[18] Tesfaye, S., Boulton, A.J.M., Dyck, P.J., Freeman, R., Horowitz, M., Kempler, P. and Lauria, G. (2010) Diabetic Neuropathies: Update on Definitions, Diagnostic Criteria, Estimation of Severity, and Treatments. Diabetes Care, 33, 2285-2293. https://doi.org/10.2337/dc10-1303

[19] Whang, R. and Ryder, K.W. (1990) Frequency of Hypomagnesemia and Hypermagnesemia. Requested vs Routine. JAMA, 263, 3063-3064. https://doi.org/10.1001/jama.1990.03440220087036

[20] Konrad, M. (2008) Disorders of Magnesium Metabolism. In: Geary, D. and Shaefer, F., Eds., Comprehensive Pediatric Nephrology, Mosby Elsevier, Philadelphia, PA, 461-475. https://doi.org/10.1016/B978-0-323-04883-5.50036-2

[21] Martin, K.J., González, E.A. and Slatopolsky, E. (2009) Clinical Consequences and Management of Hypomagnesemia. Journal of the American Society of Nephrology, 20, 2291-2295. https://doi.org/10.1681/ASN.2007111194

[22] Bringhurst, F.R., Demay, M.B., Krane, S.M. and Kronenberg, H.M. (2005) Bone and Mineral Metabolism in Health and Disease. In: Kasper, D.L., Braunwald, E., Fauci, A.S., Longo, D.L., Hauser, S.L. and Jameson, J.L., Eds., Harrison's Principle of Internal Medicine, 16th Edition, McGraw-Hill, New York, 2238-2248.

[23] Baig, M.S.A., Shamshuddin, M., Mahadevappa, K.L., Attar, A.H. and Shaikh, A.K. (2012) Serum Magnesium as a Marker of Diabetic Complication. Journal of Evolution of Medical \& Dental Sciences, 1, 119-123. https://doi.org/10.14260/jemds/20

[24] Mishra, S., Padmanaban, P., Deepti, G.N., Sarkar, G., Sumathi, S. and Toora, B.D. (2012) Serum Magnesium and Dyslipidemia in Type-2 Diabetes Mellitus. Biomedical Research, 23, 295-300.

[25] Pham, P.-C.T., Pham, P.-M.T., Pham, S.V., Miller, J.M. and Pham, P.-T.T. (2007) Hypomagnesemia in Patients with Type 2 Diabetes. Clinical Journal of the American Society of Nephrology, 2, 366-373. https://doi.org/10.2215/CJN.02960906

[26] Gommers, L.M., Hoenderop, J.G., Bindels, R.J. and de Baaij, J.H. (2016) Hypomagnesemia in Type 2 Diabetes: A Vicious Circle? Diabetes, 65, 3-13. https://doi.org/10.2337/db15-1028

[27] Dong, J.Y., Xun, P., He, K. and Qin, L.Q. (2011) Magnesium Intake and Risk of Type 2 Diabetes: Meta-Analysis of Prospective Cohort Studies. Diabetes Care, 34, 2116-2122. https://doi.org/10.2337/dc11-0518

[28] Sadiq, F. and Nawaz, M.R. (2014) Hypomagnesemia in Patients with Type 2 Diabetes. Pakistan Journal of Medical and Health Sciences, 8, 983-985.

[29] Kumar, A., Bhatti, M.S.F., Jamali, A. and Shaikh, U. (2011) Association between Hypomagnesaemia and Foot Ulcers in Type II Diabetes Mellitus. Medical Forum Monthly, 22, 55-58.

[30] Jamali, A.A., Jamali, G.M., Jamali, N.H., et al. (2018) Assessment of Serum Magnesium Level in Type 2 Diabetes Mellitus with Diabetic Foot Ulcers (Grade I and II) at Nawabshah, Pakistan. International Journal of Clinical Medicine, 9, 104-119. https://doi.org/10.4236/ijcm.2018.92011

[31] De Lordes Lima, M., Cruz, T., Pousada, J.C., Rodrigues, L.E., Barbosa, K. and Canguçu, V. (1998) The Effect of Magnesium Supplementation in Increasing Doses on the Control of Type 2 Diabetes. Diabetes Care, 21, 682-686.

[32] De Leeuw, I., Engelen, W., De Block, C. and Van Gaal, L. (2004) Long Term Mag- 
nesium Supplementation Influences Favourably the Natural Evolution of Neuropathy in Mg-Depleted Type 1 Diabetic Patients (T1dm). Magnesium Research, 17, 109-114.

[33] Jamali, A.A., Jamali, G.M., Jamali, A.A., Jamali, N.H., Tanwani, B.M., Sohail, M.A. and Rajput, A.A. (2018) Association of Low Serum Magnesium Levels in Type 2 Diabetes Mellitus with \& without Hypertension. Open Journal of Preventive Medicine, 8, 57-69. https://doi.org/10.4236/ojpm.2018.83006 